\title{
Considerations of Uncertainty in Regulatory Decision Making
}

\author{
Mark A. Cunningham \\ Senior Risk Advisor, Office of Commissioner Apostolakis \\ United States Nuclear Regulatory Commission \\ Washington, DC 20555 USA \\ Mark. Cunningham@nrc.gov
}

\begin{abstract}
NRC's approach to ensuring the safety of nuclear power includes two complementary approaches, one more deterministic and one more probabilistic. These two approaches address the uncertainties in the underlying methods and data differently, with each approach having its strengths and limitations.

This paper provides some background on the historical evolution of deterministic and probabilistic methods in the regulation of nuclear power plants, describes the Commission's policy on the use of probabilistic methods to complement the more traditional deterministic approach, and identifies some example challenges as a staff group considers a strategic vision of how the agency should regulate in the future.
\end{abstract}

Keywords: risk assessment, nuclear safety, performance-based regulation, safety goals, probabilistic risk assessment.

\section{Introduction}

Nuclear power plants in the United States historically have been licensed using Part 50 of Title 10 of the Code of Federal Regulations [1. Implementation of Part 50 has been achieved, for the most part, using deterministic methods and acceptance criteria. These deterministic methods and acceptance criteria were established originally in the 1960's and 1970's and were intentionally conservative in recognition of uncertainties in both routine operations and potential accident conditions. Concepts used included:

- A set of "design basis" accidents (DBAs) that was intended to envelope conditions from a credible set of events,

- A "single failure criterion," a qualitative approach to ensure that systems used to mitigate accidents were highly reliable,

- A "defense in depth" philosophy that introduced barriers between radioactive material and workers and the public, and

- Inclusion of safety margins, a traditional engineering approach for ensuring a robust design.

In 1975, NRC published its first probabilistic risk assessment (PRA) which examined two reactors designed using Part 50 from a different, more realistic,

A. Dienstfrey and R.F. Boisvert (Eds.): WoCoUQ 2011, IFIP AICT 377, pp. 15-26, 2012.

(C) IFIP International Federation for Information Processing 2012 
perspective 2. This study considered a broader set of possible accidents (relative to the DBAs) and estimated their occurrence frequencies, evaluated system reliability quantitatively, estimated the potential public health consequences, and measured, in effect, the effectiveness of the included defense in depth and safety margins. Public health risk was estimated, including an estimate of the uncertainties in this risk. The value of PRA, highlighted by the investigations of the 1979 accident at Three Mile Island, led to the performance of a number of PRAs on other plants and, in the late 1980's, an examination by all operating nuclear power plants for potential vulnerabilities using PRA techniques [3].

\section{Commission Policy on Use of Risk Assessment}

By the mid-1990s, the nuclear industry had gained considerable experience with implementation of Part 50 and the results of PRAs. In 1995, NRC published a statement describing, among other things, the relationship between these two views of reactor safety 4. This policy statement directed the NRC staff to increase the use of PRA, setting a course for staff activities that has resulted in a significant expansion in its use.

The Commission's policy statement summarizes the value of risk assessment as follows:

The NRC has generally regulated the use of nuclear material based on deterministic approaches. Deterministic approaches to regulation consider a set of challenges to safety and determine how those challenges should be mitigated. A probabilistic approach to regulation enhances and extends this traditional, deterministic approach, by: (1) allowing consideration of a broader set of potential challenges to safety, (2) providing a logical means for prioritizing these challenges based on risk significance, and (3) allowing consideration of a broader set of resources to defend against these challenges.

With this perspective on the value, and relative roles, of traditional and risk methods, the Commission established the following as its policy:

Increase use of PRA technology in all regulatory matters to the extent supported by the state-of-the-art in PRA methods and data and in a way that complements the deterministic approach and supports the traditional defense-in-depth philosophy.

Use PRA, where practical within the bounds of the state-of-the-art, to reduce unnecessary conservatism in current regulatory requirements, regulatory guides, license commitments, and staff positions and to support proposals for additional regulatory requirements in accordance with 10 CFR 50.109 (Backfit Rule).

PRAs used in regulatory decisions should be as realistic as practicable and supporting data should be publicly available. 
Safety goals and subsidiary numerical objectives are to be used with appropriate consideration of uncertainties in making regulatory judgments on the need for new generic requirements.

$\mathrm{NRC}$ has made significant progress in implementing this policy in the past 15 years. In the late 1990's-early 2000's time frame, the NRC staff undertook a number of initiatives to better incorporate risk insights and performance considerations into its regulatory programs. In addition to regulatory changes, the NRC worked with other organizations (e.g., the American Society of Mechanical Engineers and the National Institute of Standards and Technology) to improve the technical infrastructure underlying risk assessments. These improvements included the development of consensus standards [20], the development of new methods [21, and performing research including developing better computational methods to validate these new assessment techniques 22 . These initiatives resulted in fundamental changes to how the NRC conducts its licensing, inspection and rulemaking programs.

NRC's Commission has also directed the NRC staff to solicit input from industry and other stakeholders on performance-based initiatives, including areas that are not amenable to risk-informed approaches, to supplement the NRC's traditional deterministic system of licensing and oversight. It should be noted that deterministid 1 and prescriptive 2 regulatory requirements were based mostly on experience, testing programs and expert judgment, considering factors such as safety margins and the principle of defense-in-depth. These requirements are viewed as being successful in establishing and maintaining adequate safety margins for NRC-licensed activities. The NRC has recognized that deterministic and prescriptive approaches can limit the flexibility of both the regulated industries and the NRC to respond to lessons learned from operating experience and support the adoption of improved designs or processes.

The NRC has as one of its primary safety goal strategies the use of sound science and state-of-the-art methods to establish, where appropriate, risk-informed and performance-based regulations. The NRC issued a paper [5] to define the terminology and expectations for evaluating and implementing the initiatives related to risk-informed, performance-based approaches. That paper defines a performance-based approach as follows:

\footnotetext{
${ }^{1}$ A deterministic approach to regulation establishes requirements for engineering margin and for quality assurance in design, manufacture, and construction. In addition, it assumes that adverse conditions can exist and establishes a specific set of design basis events and related acceptance criteria for specific systems, structures, and components based on historical information, engineering judgment, and desired safety margins. An example is a defined load on a structure (e.g., from wind, seismic events, or pipe rupture) and an engineering analysis to show that the structure maintains its integrity.

2 A prescriptive requirement specifies particular features, actions, or programmatic elements to be included in the design or process, as the means for achieving a desired objective. An example is a requirement for specific equipment (e.g., pumps, valves, heat exchangers) needed to accomplish a particular function (e.g., remove a defined heat load).
} 
A performance-based regulatory approach is one that establishes performance and results as the primary basis for regulatory decision-making, and incorporates the following attributes:

1. measurable (or calculable) parameters (i.e., direct measurement of the physical parameter of interest or of related parameters that can be used to calculate the parameter of interest) exist to monitor system, including facility and licensee, performance,

2. objective criteria to assess performance are established based on risk insights, deterministic analyzes and/or performance history,

3. licensees have flexibility to determine how to meet the established performance criteria in ways that will encourage and reward improved outcomes; and

4. a framework exists in which the failure to meet a performance criterion, while undesirable, will not in and of itself constitute or result in an immediate safety concern 3

Performance-based approaches can be pursued either independently or in combination with risk-informed approaches. After the paper's issuance, NRC continued to make progress on developing policies and guidance related to performancebased approaches and subsequently issued guidance documents [6] [7].

Perhaps the most significant programmatic adoption of risk-informed and performance-based considerations in the reactor area took place with implementation of the "reactor oversight process" (ROP) [8]. The ROP, intended to focus agency reactor inspection resources in the most risk-significant areas of reactor operation, replaced the previous program with explicit consideration of risk and performance considerations. The normal "baseline" inspection program is focused on the more risk-important areas of plant operations. In addition, events or conditions at plants are assessed for significance using probabilistic risk models. The results of such assessments are used to direct additional oversight to plants with more significant findings.

A more recent reactor initiative that adopts a risk-informed and performancebased approach relates to fire protection, in which standards from the National Fire Protection Association (NFPA-805) were incorporated into NRC's regulation in 10CFR50.48(c) 9. This regulation provides deterministic requirements that are very similar to those in NRC's traditional fire protection regulations, and also includes performance-based methods for evaluating plant configurations that provide a comparable and equivalent level of safety intended by the conservative deterministic requirements. The performance-based methods allow engineering analyzes to demonstrate that the changes in overall plant risk that result from these plant configurations is acceptably small and that fire protection

${ }^{3}$ Using the previous example (footnote 2), a performance-based approach might provide additional flexibility to a licensee on plant equipment and configurations used to accomplish a safety function (e.g., removing a heat load), but the performance criteria could not be the actual loss of a safety function that would result in the release of radioactive materials. 
defense-in-depth is maintained 4 Defense-in-depth as applied to fire protection means that an appropriate balance is maintained between:

1. preventing fires from starting;

2. timely detection and extinguishing of fires that might occur; and

3. protection of systems, structures and components important to safety from a fire that is not promptly extinguished.

The adoption of NFPA 805, which is voluntary on the part of reactor licensees, provides a licensee with flexibility regarding how to implement its fire protection program while maintaining an acceptable level of fire safety.

In parallel, the NRC staff was incorporating risk insights into other regulatory areas. In the materials area, a staff document [12] was developed in the late 1990's to pull together into one place the various guidance documents written over the years for the wide variety of materials licensees. These documents allow license applicants to find the applicable regulations, guidance and acceptance criteria used in granting a materials license. Operational experience (performance) and risk insights guided the development of these documents. Over time the guidance has been revised to further incorporate risk insights, performance considerations and changing technology. A new revision to the series is under development to address security and other issues.

The materials inspection program was fundamentally revised in 2001 — both in terms of approach and frequency — in the Phase II Byproduct Material Review [13. The inspection approach was modified to emphasize licensee knowledge and performance of NRC-licensed activities over document review. Inspectors now review a licensee's program against focus areas that reflect those attributes which are considered to be most risk-significant. If a licensee's performance against a given focus element during the inspection is considered to be acceptable, the inspector moves on to the next focus element. Performance concerns or questions lead an inspector to go deeper into that area. In addition, inspection frequencies were revised based on risk insights as well as licensee performance over time.

\section{Developing a Strategic Vision}

In early 2011, an NRC staff group was established [14] to, in effect, reflect on the past 15 years of experience and to develop a "strategic vision and options for

${ }^{4}$ Building upon the guidance in Regulatory Guide 1.174 [10], "An Approach for Using Probabilistic Risk Assessment in Risk-Informed Decisions on Plant-Specific Changes to the Licensing Basis," Regulatory Guide 1.205 [11], "Risk-Informed, PerformanceBased Fire Protection for Existing Light-Water Nuclear Power Plants," states: "Prior NRC review and approval is not required for individual changes that result in a risk increase less than $1 \times 10^{-7}$ per year for CDF (core damage frequency) and less than $1 \times 10^{-8}$ per year for LERF (large early release frequency - a measure of potential offsite health consequences). The proposed change must also be consistent with the defense-in-depth philosophy and must maintain sufficient safety margins. The change may be implemented following completion of the plant change evaluation." 
adopting a more comprehensive and holistic risk-informed, performance-based regulatory approach for reactors, materials, waste, fuel cycle, and transportation that would continue to ensure the safe and secure use of nuclear material." This group was established by Chairman Gregory Jaczko and is being headed by Commissioner George Apostolakis.

When this group was established, the agency was dealing with a number of challenging regulatory issues. In several instances, the technical understanding of the issue was relatively poor, with important uncertainties in key topics. Just after the group was established, the Fukushima nuclear power plants in Japan experienced a large earthquake and tsunami. The effects of these events, and their implications to the safety and regulation of US nuclear power plants, introduced additional challenges. Some of these challenges are discussed in more detail below.

\subsection{Challenging Regulatory Topics}

Performance of Emergency Core Cooling Systems. In 2004, NRC issued a communication [15] to all power reactor licensees requesting that each perform an evaluation to address:

The identified potential susceptibility of pressurized-water reactor ( $P W R$ ) recirculation sump screens to debris blockage during design basis accidents requiring recirculation operation of lemergency core cooling system] ECCS or [containment spray system] CSS and on the potential for additional adverse effects due to debris blockage of flowpaths necessary for ECCS and CSS recirculation and containment drainage.

Since that time, power reactor licensees have made modifications, as necessary, to address the 2004 issue. However, other related issues have also been identified, including the possible effects of chemical additives on the debris characteristics, potentially worsening the blockage potential, and the potential effects of debris entering the reactor core region and causing blockages there.

In this example, decision makers are provided technical information having uncertainties in several key technical areas, including the effect on debris accumulation, and possible cooling system blockage, of chemical interactions, as well the effect of debris potentially entering and blocking portions of the reactor core area. Experimental work is underway to provide additional data in both areas, but the applicability of the results to the different reactor types also complicates decision making.

NRC staff addressed the complex technical and regulatory issues in a paper [16] providing options to the NRC's Commission for decision. The paper recommended that the ongoing staff approach be continued, which included a determination "whether, given the conservatisms, nonconservatisms, and/or uncertainties in the various review areas, the licensee has demonstrated adequate strainer performance and therefore compliance with the regulations." 
The schedule for this considered the risk of different types of accidents, such that it would "address any outstanding issues associated with more likely and risksignificant smaller loss of coolant accidents (LOCAs) (14 inches and below) in the short term, but would allow more time to address issues associated with the low-likelihood larger break LOCAs (above 14 inches). In this way, the more risksignificant issues would be closed quickly, and licensees would have the flexibility to reduce the impact (cost and dose) of addressing the less risk-significant LOCAs through planning, testing, or refined analyzes." The paper also recommended a second approach to be used in combination that "would provide more flexibility to licensees for addressing larger LOCAs than is currently permitted" using existing guidance and that would "likely reduce the scope of modifications needed to address [the issue] for some plants and would be consistent with agency policy regarding risk-informed regulation." NRC's Commission subsequently approved the recommended approach [17] with "comments and clarifications."

\section{Earthquake Frequencies in the Central and Eastern United States.} In 2010, NRC staff completed an assessment [18] of new information related to potential earthquakes in the central and eastern United States (that part of the United States east of the Rocky Mountains). In some cases, the new information indicated that estimated frequencies of earthquakes increased relative to previous estimates. Not surprisingly, these estimates had considerable uncertainty.

Since that time, NRC staff have been working to determine what, if any, actions need to be taken by power reactor licensees. A progressive screening approach is being considered which would include comparisons with deterministic information used in the initial design and, if necessary, two alternative seismic risk assessment methods.

One Impact of the Fukushima Accident. In March 2011, the Fukushima nuclear power station in Japan experienced a very large earthquake and subsequent tsunami. The resulting damage is described in a number of documents, and is summarized as follows in an NRC report [19]:

As a result of the earthquake, all of the operating units appeared to experience a normal reactor trip within the capability of the safety design of the plants. The three operating units at Fukushima Dai-ichi automatically shut down, apparently inserting all control rods into the reactor. As a result of the earthquake, offsite power was lost to the entire facility. The emergency diesel generators started at all six units providing alternating current (ac) electrical power to critical systems at each unit, and the facility response to the seismic event appears to have been normal.

Approximately 40 minutes following the earthquake and shutdown of the operating units, the first large tsunami wave inundated the site followed by multiple additional waves. The estimated height of the tsunami exceeded the site design protection from tsunamis by approximately 8 meters (27 feet). The tsunami resulted in extensive damage to site facilities 
and a complete loss of ac electrical power at Units 1 through 5, a condition known as station blackout (SBO). Unit 6 retained the function of one of the diesel generators.

The operators were faced with a catastrophic, unprecedented emergency situation. They had to work in nearly total darkness with very limited instrumentation and control systems. The operators were able to successfully cross-tie the single operating Unit 6 air-cooled diesel generator to provide sufficient ac electrical power for Units 5 and 6 to place and maintain those units in a safe shutdown condition, eventually achieving and maintaining cold shutdown.

Despite the actions of the operators following the earthquake and tsunami, cooling was lost to the fuel in the Unit 1 reactor after several hours, the Unit 2 reactor after about 71 hours, and the Unit 3 reactor after about 36 hours, resulting in damage to the nuclear fuel shortly after the loss of cooling. Without ac power, the plants were likely relying on batteries and turbine-driven and diesel-driven pumps. The operators were likely implementing their severe accident management program to maintain core cooling functions well beyond the normal capacity of the station batteries. Without the response of offsite assistance, which appears to have been hampered by the devastation in the area, among other factors, each unit eventually lost the capability to further extend cooling of the reactor cores.

The current condition of the Unit 1, 2, and 3 reactors is relatively static, but those units have yet to achieve a stable, cold shutdown condition. Units 1, 2, 3, and 4 also experienced explosions further damaging the facilities and primary and secondary containment structures. The Unit 1, 2, and 3 explosions were caused by the buildup of hydrogen gas within primary containment produced during fuel damage in the reactor and subsequent movement of that hydrogen gas from the drywell into the secondary containment. The source of the explosive gases causing the Unit 4 explosion remains unclear. In addition, the operators were unable to monitor the condition of and restore normal cooling flow to the Unit 1, 2, 3, and 4 spent fuel pools.

From a decision making perspective, this accident raises issues with respect to the ability to predict the likelihood of very large earthquakes and to decide how large of an earthquake should be considered sufficiently likely that it must be considered in a nuclear power plant's design. In addition, this example introduces other important uncertainties. One key additional issue is the effectiveness of emergency response, relied upon in nuclear safety to help ensure that the potentially affected population near nuclear power plants would not be exposed to large amounts of radioactive material.

An NRC group provided recommendations to the NRC Commission [19] that included some that reflect on how to address issues with considerable uncertainty, and the relative role of deterministic and risk assessment methods. These recommendations are currently under evaluation. 


\subsection{Some Issues to Resolve}

These example issues raise some important questions, including:

- What are the relative roles of traditional engineering approaches and risk assessment?

- Are there better ways to collect and analyze new information?

- Should performance based approaches be used to a greater extent to better reflect such new information?

- How should decision makers include consideration of very unlikely events that could result in very large consequences?

As noted above, an NRC staff group is now considering a strategic vision for a more comprehensive and holistic risk-informed, performance-based regulatory approach. This group is considering questions such as these; it expects to complete its report in the spring, 2012.

\section{References}

1. United States Nuclear Regulatory Commission (USNRC): Title 10 (Energy) Code of Federal Regulations, Part 50 (Domestic Licensing of Production and Utilization Facilities), http://www.nrc.gov/reading-rm/doc-collections/cfr/part050/

2. USNRC: NUREG 75/014, Reactor Safety Study: An Assessment of Accident Risks in US Commercial Nuclear Power Plants, http://www.nrc.gov/reading-rm/doc-collections/nuregs/staff/sr75-014/

3. USNRC: Generic Letter 88-20, Individual Plant Examination for Severe Accident Vulnerabilities, http://www.nrc.gov/reading-rm/doc-collections/gen-comm/ gen-letters/1988/gl88020.html

4. USNRC: Use of Probabilistic Risk Assessment in Methods in Nuclear Regulatory Activities, Final Policy Statement, http://www.nrc.gov/reading-rm/ doc-collections/commission/policy/60fr42622.pdf

5. USNRC: White Paper on Risk-Informed and Performance-Based Regulation, http://www.nrc.gov/reading-rm/doc-collections/commission/ secys/1998/secy1998-144/1998-144scy.pdf

6. USNRC: SECY-2000-0191, High-Level Guidelines for Performance-Based Activities, http://www.nrc.gov/reading-rm/doc-collections/commission/ secys/2000/secy2000-0191/2000-0191scy.pdf

7. USNRC: Guidance for Performance-Based Regulation, http://www.nrc.gov/reading-rm/doc-collections/nuregs/brochures/br0303/

8. USNRC: SECY-99-007, Recommendations for Reactor Oversight Process Improvements, http://www.nrc.gov/reading-rm/doc-collections/commission/secys/ 1999/secy1999-007/1999-007scy_attach.pdf

9. USNRC: Title 10 (Energy) Code of Federal Regulations, Part 50.48(c), National Fire Protection Standard NFPA 805, http://www.nrc.gov/reading-rm/ doc-collections/cfr/part050/part050-0048.html

10. USNRC: Regulatory Guide 1.174, An Approach for Using Probabilistic Risk Assessment in Risk-Informed Decisions on Plant-Specific Changes to the Licensing Basis, http://pbadupws.nrc.gov/docs/ML1009/ML100910006.pdf 
11. USNRC: Regulatory Guide 1.205, Risk-Informed, Performance-Based Fire Protection for Existing Light-Water Nuclear Power Plants, http://pbadupws.nrc.gov/docs/ML0927/ML092730314.pdf

12. USNRC: NUREG-1556, Consolidated Guidance about Materials Licenses, http://www.nrc.gov/reading-rm/doc-collections/nuregs/staff/sr1556/

13. USNRC: SECY-99-062, Nuclear Byproduct Material Risk Review, http://www.nrc.gov/reading-rm/doc-collections/commission/secys/ 1999/secy1999-062/1999-062scy.pdf

14. USNRC: Charter for Task Force for Assessment of Options for More Holistic RiskInformed, Performance-Based Regulatory Approach. ADAMS document access system, accession number ML100270582

15. USNRC: Generic Letter 2004-02, Potential Impact of Debris Blockage on Emergency Recirculation during Design Basis Accidents at Pressurized Water Reactors, http://www.nrc.gov/reading-rm/doc-collections/gen-comm/ gen-letters/2004/gl200402.pdf

16. USNRC: SECY-2010-0113, Closure Options for Generic Safety Issue-191, Assessment of Debris Accumulation on Pressurized Water Reactor Sump Performance, http://www.nrc.gov/reading-rm/doc-collections/commission/secys/2010/ secy2010-0113/2010-0113scy.pdf

17. USNRC: Staff Requirements - SECY-2010-0113 - Closure Options for Generic Safety Issue-191, Assessment of Debris Accumulation on Pressurized Water Reactor Sump Performance, http://www.nrc.gov/reading-rm/doc-collections/ commission/srm/2010/2010-0113srm.pdf

18. USNRC: Safety/Risk Assessment Results for Generic Issue 199, "Implications of Updated Probabilistic Seismic Hazard Estimates in Central and Eastern United States on Existing Plants." ADAMS document access system, accession number ML100270582

19. USNRC: Recommendations for Enhance Reactor Safety in the 21st Century, http://pbadupws.nrc.gov/docs/ML1118/ML111861807.pdf

20. ASME/ANS: ASME/ANS RA-Sa-2009, Standard for Level 1/Large Early Release Frequency Probabilistic Risk Assessment for Nuclear Power Plant Applications, Addendum A to RA-S-2008. ASME, New York (2009)

21. USNRC and Electric Power Research Institute: NUREG/CR-6850, EPRI/NRCRES Fire PRA Methodology for Nuclear Power Facilities, http://www.nrc.gov/reading-rm/doc-collections/nuregs/ contract/cr6850v1.pdf

22. USNRC: NUREG-1824, Verification and Validation of Selected Fire Models for Nuclear Power Plant Applications, http://www.nrc.gov/reading-rm/doc-collections/nuregs/staff/sr1824/ 


\section{Discussion}

\section{Speaker: Mark Cunningham}

Philip Starhill: Presumably the landscape of low probability events is much more diverse than that of higher probability events. How does that impact the utility of deterministic modeling of low probability events?

Mark Cunningham: The estimation of very low probability events, such as very large earthquakes or floods, or the failure probability of very large pipes used in nuclear power plants, is a particularly challenging aspect of nuclear safety analyzes. Historically, nuclear safety organizations such as NRC have made conservative deterministic statements on what magnitudes of earthquakes or sizes of pipe breaks needed to be considered in plant designs. These statements included, of course, some consideration on the credibility of the specified earthquake or pipe break, which was tied to some perception at the time of their probability. Modern risk assessment methods supplement these statements by including more quantitative probability estimates. Expert interpretation of available information, and the translation of such interpretations in statements of probability, is used for low probability events. This approach, especially when a number of experts are used, has been found to be an acceptable method when sufficient data are not otherwise available.

Van Snyder: A numeric limit is established for risk of death within a specified distance due to nuclear power plant operations. Has there been a quantification, and limit, of total system risk to the public at large, and a comparison of that total system risk to total system risk from alternatives, especially coal?

Mark Cunningham: In 1986, NRC established "safety goals" for the operation of nuclear power plants. These goals were intended to ensure that public risk from nuclear power plant operations was a small fraction of other risks, including the risks from other forms of electric power generation. Risk assessments performed by NRC indicate that nuclear power plants meet the established safety goals. NRC has not made comparisons between, for example, risks from electric power generation from coal. Some such studies were performed, however, by staff at Oak Ridge National Laboratory a number of years ago.

William Kahan: If I remember correctly, burning coal releases Radon; and coal ash is very weakly radioactive, but there is a vast amount of it to be stored. When the totals of radioactivity liberated by coal mining are added up, do they bring the coal industry under the purview of the Nuclear Regulatory Commission? Should they?

Mark Cunningham: The coal industry is not subject to regulatory review by NRC. Since its establishment in 1975 by Congress, the scope of NRC's statutory authority has been discussed by Congress to possibly include, for example, Department of Energy facilities using nuclear materials. To my knowledge, these discussions have not considered the coal industry. 
Jeffrey Fong: My question is on stability of operation. After deregulation, electricity is being treated as a commodity purchased every six minutes. This creates instability and pressure on operators. Does NRC have new regulations to address this type of operational instability?

Mark Cunningham: When deregulation was beginning to occur, NRC recognized that nuclear power plant operations could be impacted by deregulation of the electrical energy market, and reassessed its regulatory approach. To my knowledge, no new regulations were established specifically to address the possible effects of deregulation.

Jeffrey Fong: Do risk assessment standards include quantitative estimates of human errors during all phases of nuclear reactor operations?

Mark Cunningham: Yes, risk assessments do include quantitative consideration of human errors. 